\title{
Incidence of ligamentous laxity and scoliosis among the population of the United Arab Emirates
}

\author{
K Bagnall, H Al Hamsi, A Al Kaabi, T Al Mazrouee, A D'souza \\ From 8th International Conference on Conservative Management of Spinal Deformities and SOSORT 2011 \\ Annual Meeting \\ Barcelona, Spain. 19-21 May 2011
}

\section{Background}

Among a general lack of awareness of scoliosis, the incidence of Adolescent Idiopathic Scoliosis (AIS) in the United Arab Emirates is not known although efforts are currently being made to remedy this. The Emirati people have a unique and well-structured culture with strong family relationships and might be considered a closed group. Consequently, there are some factors within this group that suggest that the incidence of AIS might be higher than in other parts of the world. In this study, the incidence of ligamentous laxity among young Emirati women was measured because this has been associated many times previously with AIS and casual observation has suggested that ligamentous laxity is prevalent among many young Emirati women.

\section{Material and methods}

The degree of extension of the middle metacarpoproximal-phalanx joint and thumb abduction were measured on both hands using standard, previously reported techniques of 100 randomly-selected, young Emirati women. The results were compared with similar published data from the United Kingdom.

\section{Results}

The results showed that there was a higher incidence of ligamentous laxity among the emirati population in both the degree of extension of the middle metacarpoproximal-phalanx joint as well as thumb abduction when compared to the values from the UK.

UAE University, Al Ain, United Arab Emirates

\section{Conclusions}

These results suggest that the incidence of AIS in the UAE (when determined) might be expected to be greater than in other parts of the world due to a higher incidence of ligamentous laxity among the susceptible population.

Published: 27 January 2012

\section{doi:10.1186/1748-7161-7-S1-070}

Cite this article as: Bagnall et al:: Incidence of ligamentous laxity and scoliosis among the population of the United Arab Emirates. Scoliosis 2012 7(Suppl 1):070.
Submit your next manuscript to BioMed Central and take full advantage of:

- Convenient online submission

- Thorough peer review

- No space constraints or color figure charges

- Immediate publication on acceptance

- Inclusion in PubMed, CAS, Scopus and Google Scholar

- Research which is freely available for redistribution
() Biomed Central 